\title{
Chronic pneumonitis of infancy
}

INSERM

\section{Source}

INSERM. (1999). Orphanet: an online rare disease and orphan drug data base. Chronic pneumonitis of infancy. ORPHA:91359

Chronic pneumonitis of infancy is a rare pediatric form of interstitial lung disease (ILD, see this term). 